\title{
PIP Kit: An Exploratory Investigation into using Lifelogging to support Disability Benefit Claimants
}

\author{
Colin Watson \\ Newcastle University, UK \\ c.watson8@ncl.ac.uk
}

\author{
Reuben Kirkham \\ Monash University, Australia \\ reuben.kirkham@monash.edu
}

\author{
Ahmed Kharrufa \\ Newcastle University, UK \\ ahmed.kharrufa@ncl.ac.uk
}

\begin{abstract}
Disability assessment processes are complex and stressful, with claimants finding it challenging to prepare an effective account of their disabilities to support their claim. This project focuses on a disability benefit called Personal Independence Payment (PIP), which is received by millions of people with disabilities in the UK. We present a multistage exploratory investigation into how lifelogging could help address the challenges claimants have in accessing disability benefits. In the first study, benefit advisors participated in interviews and workshops to inform the design of PIP Kit, a highly customisable prototype elicitation diary to help disability claimants articulate their experiences. In the second study, PIP Kit was trialled by benefit claimants whilst making their actual PIP claims. We found that PIP Kit helped empower claimants in understanding the claim process and assisted in building arguments for their claims. We also have identified clear principles for supporting disability benefit claimants with technological interventions.
\end{abstract}

\section{Author Keywords}

Accessibility; Disability; Social Security

\section{CSS Concepts}

- Human-centered computing Human computer

interaction (HCI); Human-centered computing

\section{INTRODUCTION}

Disabilities and health conditions often involve increased financial costs of living [29], as well as a reduced opportunity for gainful employment [7]. To help defray these additional costs and to provide replacement income, many countries have a 'welfare state' that provides social security benefits for those deemed to be 'disabled enough'. We consider disability benefits intended to offset the extra costs of living, which are separate to other support made to help with reasonable accommodations [60]. These systems are bureaucratic involving complex legislation, multifarious assessments, and multistage adjudicative processes, imposing burdensome activities on claimants making and maintaining claims [33]. In respect of disability benefits, the

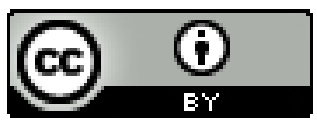

This work is licensed under a Creative Commons Attribution International 4.0 License.

CHI'20, April 25-30, 2020, Honolulu, HI, USA

(C) 2020 Copyright is held by the owner/author(s)

ACM ISBN 978-1-4503-6708-0/20/04

DOI: https://doi.org/10.1145/3313831.3376215 effect is to reduce the complexity of a person's impairments to a number: how much (if anything) a claimant will be paid. This is frequently a difficult, embarrassing and distressing experience [2], often made harder by their health conditions [27], which negatively affects claimants' mental and physical health and wellbeing [57], and where claimants often fail to persuade the government of their entitlement [73] leading to significant financial disbenefit.

Many claimants rely upon specialist (and hard-pressed) advice agencies [26], whose staff and supervised volunteers support them in articulating their experiences. In close collaboration with one of these advice agencies, we investigated the potential use of lifelogging to assist people with disabilities to capture and articulate a thorough description of true life events sufficient for the types of information required by regulation, in the context of UK Personal Independence Payment (PIP) [24]. Lifelogging is an ideal medium for considering this challenge, given the emphasis placed by this framework on patterns of impairments and experience over a period of time. We conducted two closely connected exploratory qualitative studies. Firstly, we worked with advisors to identify constraints, clarify ethical issues and inform the design of PIP Kit, a prototype lifelogging tool to help claimants articulate the effects of their conditions. Secondly, we then trialled the prototype with a small number of benefit claimants to gather information on how PIP Kit helped them from their perspectives whilst making their own claims.

This paper is the first such work that we are aware of which is aimed at exploring how advice agencies and claimants alike can be supported by lifelogging technologies in making a claim. We found that PIP Kit was effective in smoothing the process, making the experience of the claimant less distressing and identifying potential arguments that would have not otherwise emerged. Our work has also identified a number of principles, including process simplification, visual cues and photography, flexibility and control, and an emphasis upon aesthetics for successfully designing supportive technologies for disability benefits claimants.

\section{BACKGROUND AND RELATED WORK}

\section{Administration of Disability Benefit Assessments}

An integral component of the welfare state are disability benefits. Setting the level of this benefit often involves reducing a multitude of conditions and effects into relatively few categories using approaches based on impairment, functional limitation, or disability [10]. Assessments vary by 
jurisdiction but typically involve some combination of medical evidence and assessor discretion [69], with a later judicial stage before a tribunal if a claimant is dissatisfied [5]. The UK's systems have been reformed to make eligibility more difficult and reducing payments [68]. There is a need to make these more humane for the millions of UK claimants [27], and identify best practice for the 6\% OECD working-age population receiving disability benefits [52].

From a practical point of view, such an exercise presents a wide range of significant challenges. First, it has been long recognised in HCI that when designing technologies used by people with disabilities, this is best done in an inclusive [72] and sensitive $[18,51]$ fashion that fully reflects the nuances of experience [61]: yet this has not been done for disability benefits systems. Second, the topic of health is inherently sensitive, which in turn means that interactions with health professionals can be limited by embarrassment [44]. Third, there is a stigma commonly associated with claiming benefits [9,71]. Fourth, some people are largely dependent on their disability benefit to have a reasonable life, and these processes are often to consider if that benefit should be withdrawn or reduced. Fifth, claimants have to recall accurately [22] how their conditions affect their daily lives; yet many involved will also have disadvantages in communicating directly arising out of their impairments [14]: indeed, the most common condition of PIP claimants is recorded as "psychiatric disorder" [27]. This task is made more difficult for claimants by the need to gather evidence and present facts on complex forms [23] in a manner that matches the (often abstract) assessment criteria [53]. These also raise practical research challenges, including possible difficulties obtaining informed consent [50], persuading participants to take part [46] and role definition [13].

\section{Diaries and Lifelogging as Evidence Capture}

Lifelogging encompasses using digital technology, often passively, to record individual's daily experiences ranging from the comprehensive to the partial and selective [34]. It provides an opportunity to "augment human memory beyond simple reminders and actually improve its capacity to remember" [36]. In respect of documenting health conditions and impairments, this has been realised by a variety of approaches, be it quantified-self tracking used to help people understand their own health conditions [59], or photo-elicitation visual lifelogging [11], which captures images of daily experience. These approaches have advantages that are particularly helpful for people with health conditions: as well as being particularly helpful for people with memory impairments, SenseCam [39] has also helped provided insight into everyday events, encouraging participants to make new associations [16]. Extendability and adaptability have been shown to be beneficial in meeting everyday practical and emotional needs [6]. Mediaelicitation is generally less-burdensome than answering questions and provides some independence of observation [16] as well as helping people communicate [3]. However, none of these approaches have been tested in the context of benefits claims, with the difficulties that context brings.

Related to lifelogging is the use of feedback diaries, which ask participants to answer predefined questions about events [41]. These can be "handheld/electronic data collection" or "paper and pencil" with some "augmented" by reminder messages [12,41]. A widely used approach towards using diaries to capture episodic events is the experience sampling method (ESM) [8], which collates both subjective and objective measures [21]. A simpler variant is the day reconstruction method (DRM) which can be used to gather data once per day [47] and is already used to help people understand their health conditions $[38,62]$. They can also be situated in the home setting, which helps people convey sensitive, embarrassing or distressing information [44], identify "invisible" effects [30], as well as assist in addressing the fact that later recall of the effects of impairments is prone to error and subjective, whilst being particularly influenced by emotional experiences [43].

\section{Digitisation of Public Services and Online Justice}

Another important aspect of our context is the recent impetus to move both public services and tribunals online. This has brought digital exclusion challenges including the trend for advice provision moving to online channels [70], poor digital literacy [4] and lack of suitable online devices and inadequate internet access [35]. There has also been growth in online civic "self-help" resources, but there are concerns about inclusivity with these tools [32,54]. Online processes have been introduced more slowly in the adjudicative context: to date, only the Civil Resolution Tribunal in British Columbia [58] is truly online in entirety, however there are ambitions in other jurisdictions to achieve the same result, with the UK planning on having an 'online court' by 2022 [56]. Attempts at adjudicating cases online with vulnerable claimants have been shown to reduce their access to a fair process, for example in immigration in the USA [28,64].

\section{INVESTIGATING PERSONAL INDEPENDENCE PAYMENT}

This work follows a case study approach that examines the UK process for disability assessments in obtaining a benefit known as Personal Independence Payment (PIP). Assisted claim form-filling is a collaborative process between claimants and advisors, and our study was designed to give equal weight to the views of both. As claimants often find the PIP process deeply distressing, we considered having them relive the process in a formative co-design exercise would be inappropriate. We therefore first worked with advisors (in Study 1) to identify the core constraints which claimants are not always aware of (e.g. legislation, resources) and undertake the design of a prototype with experienced advisors in advance of working with claimants. It involved ideating based on concepts from experience sampling [55] and using the day reconstruction method [43]. Study 2 then focussed on the claimants themselves using an exploratory prototype [31], offering a concrete opportunity for claimants to express their views as to future tools. These 
claimants were at the stage of preparing their PIP applications and service users of the same advice agency. Given the somewhat specific nature of the PIP system, we overview below its core aspects, so the task of a claimant and their advisor can be fully understood.

\section{The Entitlement Provided under PIP}

The legislative requirements of PIP [66] for making a claim are inherently analogous to lifelogging. The entitlement to PIP is based on a points-based system, where claimants must map the effects of their long-term ill health or disability to specific descriptors of activities in respect of the two components of 'mobility' and 'daily-living' [66]. Lifelogging provides an opportunity to collect information over longer periods rather than relying on recollection. These criteria are continually changed by the development of caselaw in the Courts and Tribunals, or occasional changes to the legislation by the Government of the day. There are 'standard' and 'enhanced' payment rates for each component. A claimant must score 8 points or more to receive a benefit at all at the 'standard' rate for the component in question, if they score over 12 points, then they receive an 'enhanced' rate. A claimant meets a descriptor only if they are able to do the activities "safely", "to an acceptable standard", "repeatedly" (insofar as the "activity being assessed is reasonably required to be completed"); and "within a reasonable time period" (i.e. "no more than twice as long as the maximum period" as it would take someone without a disability) [67]. Lifelogging of actions can help identify repeatability. To give an example, one of the 12 descriptors is "Planning and following journeys". To obtain points, they could show that they "need prompting to be able to undertake any journey to avoid overwhelming psychological distress" (4 points) or alternatively that "cannot plan the route of a journey" (8 points), or they "cannot follow the route of an unfamiliar journey without another person, assistance dog or orientation aid" (10 points / 12 points if the route is instead "familiar") or that they "cannot undertake any journey because it would cause [them] overwhelming psychological distress" (10 points). Notably, psychological distress varies over time, likewise with many cognitive impairments, meaning that lifelogging could be invaluable for documenting the relevant patterns.

\section{Making an Initial Claim for PIP}

New claimants begin by telephoning the Department for Work and Pensions (DWP) to undertake some basic eligibility checks. The DWP will post the 56-page paper form, which must be completed and then returned within one month [24]. As with similar assessments elsewhere [60], the PIP claim form requires that answers are given to a specific set of questions concerning activities [23] and supporting evidence provided, especially medical $[19,23,49]$. The claim form's questions and assessment criteria are often misunderstood and misinterpreted by claimants [53]. Seemingly minor details are difficult to identify and document in a claim, or challenge without experienced help. Therefore, claimants may seek assistance from local authorities or other organisations that provide help, support and guidance (i.e. advice agencies). Yet, these advisors still need the claimant to accurately explain the needs resulting from their conditions.

\section{How are Claims Assessed?}

The nature of the assessment is important for understanding the expectations and challenges in making a claim for PIP (and the implications of not initially succeeding in a claim). Once a claim is submitted, it is first sent to a civil servant in the DWP who decides if a health assessment is required. In practice, most claimants are subsequently asked to undertake a health assessment to score each activity [22]. After the assessment (if required), a DWP official will issue a decision within a few weeks. At this point, $44 \%$ of new claimants receive an award [27], but these are time-limited to between 9 months and 10 years [25] and claimants may challenge the decision using a mandatory reconsideration (MR) request. If a claimant is still dissatisfied, they may appeal to an independent tribunal (the FTT [63]) at an oral hearing, which comprises a judge, a medical member and a 'disability qualified' member: in the UK, over $75 \%$ of such appeals succeed [27]. In around $1 \%$ of cases, appeals are made to the Upper Tribunal, which deals with 'errors of law' in the FTT and has a 'law setting' function which it exercises regularly.

\section{STUDY 1: ADVISORS}

\section{Participants and Recruitment}

In Study 1, participants were all staff (employees or volunteers) at the advice agency. These advisors were invited to attend an individual interview or workshop. The study recruited 13 advisors - four in interviews (A1-A4) and nine others in workshops (A5-A13), five in one workshop and four different advisors in the second workshop.

\section{Design and Overview}

The study sought to understand constraints and advisors' interactions with service users requesting, preparing for and attending appointments and define requirements and principles for a prototype. The study comprised an initial probe, two workshops, four interviews, and design requirements analysis for construction of a prototype. The emphasis was upon obtaining rich accounts from the participants of their knowledge and experience of working with service users.

Probe: A short qualitative survey was conducted to gather data on appointment issues to inform the subsequent workshops, and also to raise the profile of the study helping with later participant recruitment. Two identical plywood boxes were designed and constructed to hold an instruction sheet and double-sided printed response cards (Figure 1A) one box to report on appointments where the service user did not attend, and one box to report on appointments which were affected by other issues. Each card had questions to document the type of meeting, when it was planned and what went wrong. The anonymous data was collected over 17 working days with a card completed as needed and placed back into the box for collection by the researchers. 


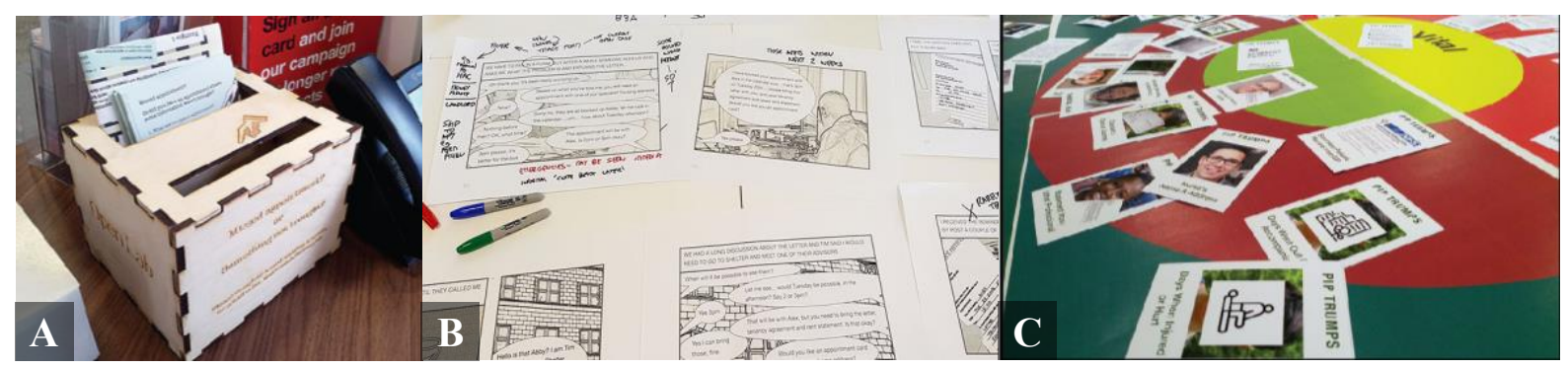

Figure 1: (A) Response card dispenser and collection box. (B) Annotations added by participants to a pre-prepared draft interaction storyboard. (C) The PIP appointment supporting evidence sorting exercise in progress.

Interviews: Four individual semi-structured interviews asked about participants' experiences of service users preparing for and attending appointments (how appointments are arranged, no-show issues, missing information, PIP form-filling experiences and use of diaries). The data was used to inform the content of the workshops as well as gather further requirements for the prototype.

Workshop 1: The purpose of the first 2-hour workshop was to understand existing appointment booking systems, interactions with service users and how information on what is required at appointments is shared. In the first activity a pre-drafted storyboard of the appointment process (Figure 1B), based on the lead researcher's previous experience at the advice agency, was presented and used to initiate a conversation about what steps actually occur; the storyboard was annotated with corrections and additions. In the second activity, the participants were given 20 paper sheets listing 33 common appointment documentation requirements (e.g. prescription list, tenancy agreement, bank statement, national insurance number). Each of the 20 sheets had a different appointment type written on them. Participants were asked to attach larger self-adhesive orange dots on the most important documents for each appointment type and smaller red dots for other useful documents. Participants could also write on the sheets to add items that were not already listed. The final activity asked participants to draw a new storyboard for an idealised process for service users booking and attending their appointments.

Workshop 2: The second 2-hour workshop explored the specific information requirements for PIP appointments in greater detail and how diaries might support claimants' preparations. The first activity was designed to identify and prioritise the most useful supporting evidence by closed card sorting. Small cards were pre-printed to include all the different possible types of information suggested as evidence on the PIP claim form (e.g. summary patient record from GP, prescription list, care plan), and using data from the interviews and first workshop other information sometimes brought by claimants (e.g. hospital appointment letters, letters of support, previous award decisions), and some which might be produced by a prototype diary (e.g. photos of aids, day-to-day variation, frequency of fits or seizures). A large bulls-eye target sheet was laid out on desks, where the most vital evidence is placed centrally, and the upper/lower split identifies whether claimants typically bring the item. Participants took turns at picking, describing and placing a card, until all were used and a photographic record made of the final placements (Figure 1C). The next activity involved a semi-structured discussion of diary use more generally with samples of medical and well-being diaries as discussion aids. Lastly some mock ideas for different types of digital and non-digital PIP diaries were discussed to consider relevance to PIP, service user acceptance and technical feasibility.

\section{Data Analysis}

The interview and workshops were audio recorded and transcribed. Given the wide variety of inputs, individual topics were extracted and the affinity diagramming method (grouping related information into clustered themes) [40] was used to organise the ideas, opinions and issues, and to identity principles, challenges and key design requirements for the prototype.

\section{FINDINGS: ADVISORS}

\section{Advisor Experiences of PIP Claimants}

Matters Affecting Appointments: A significant challenge arises from missed or ill-prepared appointments due to the reduced ability to help with issues and the effect of reducing appointment availability is already resource-constrained advice agencies.

Complexity of Claim Form and Process: The PIP claim form is challenging for claimants. A12 explained the forms are "far more complex than many forms people do in life". A11 explained that the PIP form is "tricky" and "difficult for anyone to deal with" even though the PIP claim form tries to "close down the questions" as an affordance with the goal of assisting the claimant. The general picture presented by advisors from the interviews and workshops was that most claimants are overwhelmed by the PIP claim form and process. A10 noted "they do not know what to do". A11 noted "the [health] assessment is sort of universally demoralising and depersonalising" and claimants "often have mental illness or learning difficulties or it might be language issues that makes it more difficult".

Claimants' Need for Support: Claimants themselves often seek help from advice agencies to complete the form. Our participants raised concerns about service user literacy, 
confidence with technology and whether there is sufficient order in people's lives. A10 explained many "people just don't know what to do". A11 said they realise "how significant the consequences of it are [financially]", which is a motivator for obtaining assistance.

\section{Technology Considerations}

Access to and Acceptance of Digital Technologies: The prevailing view was that "most clients have smartphones" (A1, A12) except for those in severe hardship (A11). Email was thought to be less widely used with A3 saying "there's a lot that do, and there's a lot that don't" and many "don't access them... [or] are not very confident with them". Regarding online technology more generally, A11 stated "people won't use stuff that is specifically online" but they have "incredible tolerance for stuff that's on their phones", suggesting this format is more appropriate.

Promotion of Engagement: Claimant passivity can be countered by providing choices and asking claimants to make decisions. If a process is too passive, "people are quite keen for us to do everything" and instead "you want them engaged" (A11) so the correct information is provided. A5 considered that you should "invest the client in the appointment" by asking them to make decisions, even something like their preferred day and time, with A10 saying "it's about getting the client engaged... and them to tell you" to make choices to suit their own preferences. A6 observed that "because they make that decision" they "own something in this process". A8 said by engaging with service users in a way that empowers, it "helps you take the next [step]".

Adaptability Rather Than Standardisation: Flexible service systems that can be adapted by and for people are needed for this first stage. For example, A2 said it was necessary to check individual's own circumstances whether it was safe to send SMS messages, for example in " $a$ sensitive case, like domestic violence". A8 thought "there has to be a human element in the process" and if contact is done in the wrong way "it increases the amount of work that you do".

\section{Lifelogging Diaries to Obtain Evidence and Information} Collecting Appropriate Supporting Evidence: One substantial challenge faced by claimants is knowing what evidence to provide to support their case. "Up-to-date... medical evidence" (A1) is often the most important supporting information for PIP claims. The positioning of cards in the first activity of Workshop 2 confirmed this. "Quite often they don't have anyone involved" apart from their GP so there is little evidence "it's quite hard to make the case" (A1). Interviewee A1 also assists with PIP formfilling appointments at a different advice agency where they "see a lot more people with stated mental than physical conditions.... anxiety and depression" and who "bring a lot of supporting information" and "some of it's relevant and some of it's just old". A1 noted some bring very little but that can be because of their conditions and state of mind.
Helping Claimants Focus on Effects Rather Than Conditions: Claimants often focus too much on their conditions and symptoms instead of the effects of these on their daily living and mobility which is what is being assessed. A1 and A10 noted that claimants may be experts on their own medications and treatments, but for PIP claims you do not want to "reel off the symptoms of this condition" (A10) and certainly not use "stock phrases" (A12).

Normalisation of Claimants' Conditions: Claimants have difficulty identifying and articulating their own experiences and accurately self-assessing their situations; A11 said it is difficult for a lot of people to "articulate the problems [they have themselves]" and A10 noted people "become conditioned that is quite normal" and do not always recognise that what they are doing is different "what's normal to them... is not". A12 said "some people aren't even aware [the condition] is really affecting them, because they just think it has become the norm".

Use of Lifelogging Diaries: Diaries could help change the focus to effects and generate supporting information for discussion. It was observed that some form of diary might counteract this normalisation and which A10 thought could encourage reflection "before they come to the appointment". Being able to "reference things" (A2) makes discussions at appointments easier. Diaries could help balance the "extremes" of bringing too little or too much information (A1 and A3). A1 had seen claimants who had brought in a diary to a PIP form-filling appointment which "sometimes I copy it and put it in with the form if that's relevant". A12 noted "I've never yet had anybody bring [diaries], even though they might be quite useful" and "I wish some of them would because there are obviously some people who... struggle to recall".

Need for Simplicity: A10 said it would have to be "very simple... for our clients" and that example paper form diary templates from two organisations were "good, but too complicated" (A12) and too much "like filling in a PIP form" (A10) with questions "still not understood by so many people" (A11). Regarding the method of diary completion, A11 liked the paper card with stickers concept "because it ...isn't a huge amount of work". A5 stated "whatever you do has to be done with the particular client in mind". In respect of the extent of the work required, A10 had concerns "about having many cards" being excessive for claimants to handle.

Use of Photo Elicitation: In terms of using photographs to gather information, advisor A11 thought they "would work as a conversation starter, or something like that" but "not probably going to be evidence you're going to submit". A12 thought it might be easier to get relevant details for the claim because "some people are reticent to give you details". A2 thought that having materials to discuss together "you can break down things a lot easier" and discussion is simpler when there is something "in front of us". A11 noted that photos from home might be "similar to stories... you go in and they can carry on ..." from the pictorial prompt. 


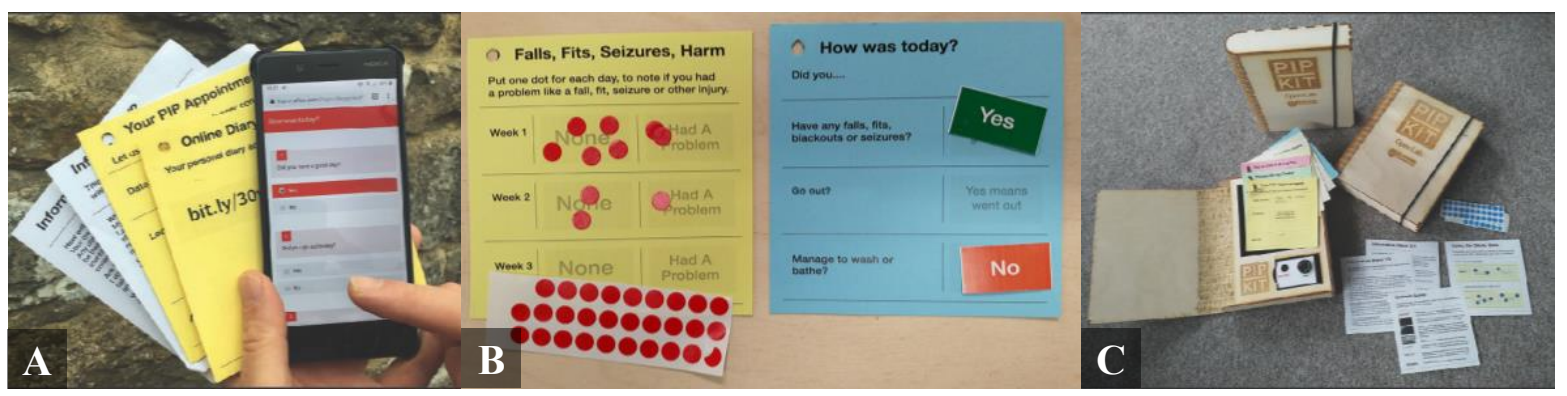

Figure 2: An illustration of PIP Kit, comprising (A) the Smartphone-compatible daily diary web form, (B) the paper card daily diary options (as an alternative to A: see the Supplementary Material) and (C) the Camera, card modules and physical components.

\section{STUDY 2: BENEFIT CLAIMANTS}

\section{Working Ethically with Disability Benefits Claimants}

The aim of Study 2 was to supplement Study 1 by exploring from claimants' viewpoints how lifelogging could contribute to both a more accurate PIP claim, and how this might be a more humane process from the perspective of claimants. Using the feedback provided in Study 1, a prototype (PIP Kit) was developed and used to assist with (real) claims. Given the potential risk to claimants being participants, the University Ethics Committee's foundational principle was that the process must be materially identical to the normal advisor process. The most challenging implication was that the researcher had to assume the role of being the advisor (putting them in a position akin to nurse practitioners in research $[17,37]$. This was primarily because the sensitivity of the topic meant that an additional person present or recording would have risked the claimant being less forthcoming and thus impact their claim. A second concern was that having two advisors (as opposed one) would have reduced appointment availability; advice agencies are resource-limited, so this would have delayed both our participants, and other clients unconnected with the study.

In the event, there were five core protections we put in place, most of which parallel those used for nurse practitioners [42]. First, the researcher responsible for engaging participants was fully trained (by the partner advice agency) and highly experienced in advising PIP claimants and assisting them to complete claim forms. Second, we ensured potential claimants had full mental capacity to take part and provide informed consent, following the test under the Mental Capacity Act (2005) [65]. Claimants were initially triaged and referred to the researcher by the advice agency, with only those appearing to meet this requirement being referred on to the researcher. The researcher then further assessed using a prepared worksheet to check the claimant was within the study's approved included groups, that they presented themselves well engaged and not unduly stressed, that language was not a barrier, and that there were no previous warning flags in the advice agency's records.

Third, to avoid any conflict of interest, this study was fully supervised by the partner agency with clear protocols agreed to ensure that clients were always protected, noting the fact that there was an unequal relationship, given the participants' need to claim benefits which can have a significant financial impact, and the need to discuss sensitive topics that can lead to stress and anxiety. Fourth, for those who used PIP Kit, the prototype was operated in parallel with the advice agency's processes and had additional redundancy to ensure that any failures or errors in methods would not be detrimental to the participants. Finally, there was a stringent approach towards data protection, with no claimant identifiable information or contact details stored or processed outside the advice agency's own IT systems, and the final claim forms themselves were not used as research records.

\section{PIP Kit Prototype}

PIP Kit comprises four primary functions: (1) Daily diary record-keeping; (2) Photographic evidence gathering; (3) Documenting supporting information requirements for the form-completion appointment, and its scheduled date and time and (4) Reminders to complete the diary, take photos, gather supporting evidence and attend the appointment.

\section{Content Modularity}

PIP Kit avoided using the poorly understood PIP assessment activity classifications [22] unlike the paper diary templates available from other sources [19,20,48,49]. Workshop 2 had suggested instead to focus on the frequency and variability of the effects of their health conditions so that these could inform the discussion at the form-completion appointment.

The set of diary modules created were: (i) Good and bad days (ii) Going out, (iii) Toilet problems, (iv) Washing/bathing problems, (v) Falls, fits, seizures, harm, (vi) Medications/ Treatments and (vii) Eating problems. Each diary module was made available as both an optional question for inclusion in an online form completed by the claimant each day, or an optional printed diary card in two permutations (either blue cards with up to three module questions per card, or one yellow card per module for the whole period with each row representing a week - see Figure 2B) which could be assembled into a single physical diary pack. Due to the preference for simplicity identified by advisors, and to align with the emphasis on daily needs in the PIP form, each diary module, whether online or physical, only asked the claimant to record whether each day was good or bad, whether they went out or not, whether they had toilet problems or not, and 
similarly for the other modules. Additional granularity of answers was thought to increase complexity in the day-today recording but was not required because this detail would be discussed with each claimant when reviewing their completed diary. To cater for individual conditions and their effects, only between two and four most appropriate seven modules were revealed and suggested to each claimant. This was to reduce claimants feeling overwhelmed and to make it easier for them to focus on the most important subset of matters that would assist subsequent form completion.

\section{Alternative Technology Components}

The concept of using a generic digital action camera had been well-received in Workshop 2 as a way to gather information under the claimant's full control and without it impacting on their own devices or requiring unusual technical skills. PIP Kit therefore includes a camera (Vibe 1080p HD) for claimants to take time-stamped pictures of aids or treatment devices they use at home, and environments (typically bathrooms, kitchens and stairs) that cause them particular difficulties, so the photos could be used to start conversations around living with their conditions. The camera was wrapped with a printed card cover to label functions and hide unnecessary controls. The photos were only stored on the camera device itself, which had an in-built display screen so these could be viewed together with the advisor. The choice to take pictures and whether to show them remained under claimants own complete control. The memory card was given to the claimant or erased after use.

Given the technology constraints identified in Study 1, PIP Kit was built to avoid installing apps on service users' phones, and instead uses technologies that advisors felt claimants would be familiar and confident with: photos, mobile-compatible web app, and paper \& pen to capture structured solicited qualitative diary data. The prepared diary content modules were made available digitally as questions in an online form version with the questions customised to the claimant (Figure 2A), or as self-completion selected paper cards which could either be completed each day by using self-adhesive dots on yellow cards, or a record of status made by taking a photograph of a daily summary blue card (Figure 2B) depending upon each claimant's preference. PIP Kit was also furnished with capabilities to send email or SMS messages to prompt diary record creation, photograph taking, and appointment reminders if a claimant wanted. A physical appointment card was also added to each PIP Kit.

\section{Presentation and Packaging}

Study 1 had identified the poor experience people have making a claim and being assessed. Pre-prepared parts and simple just-in-time fabrication methods ensured the component selection and assembly of the diary modules could be undertaken promptly with the claimant in attendance. The prototype parts look and feel as different as possible to the PIP form, or anything medical-related (Figure 2C) to counter the reported "depersonalising" and "demoralising" situation. The camera and physical components could be given to the participant in either a plain bag or a custom made natural-looking laser-cut plywood book box. This provided a customisable hybrid physicaldigital prototype for deployment.

\section{Participants: Prototype Deployment}

Out of 12 potential claimant participants who approached the advice organisation considering claiming PIP, only three (C1-C3) started and fully completed the process over the 13week study period. The others were excluded by not proceeding to make a claim (including on two occasions where it was felt a claim would not beneficial to the otherwise claimant, e.g. the risk of losing an existing award), not having time to participate, not being able to attend due to mobility issues, not being deemed capable of informed consent, or declining to take part. Two participants recorded information for one week, and one for three weeks.

\section{PIP Kit Deployment Trials and Data Analysis}

At an initial appointment with each claimant the choice of modules and components were discussed, and notes added to the diary to confirm what other documentation should be brought as supporting evidence. Each participant took their PIP Kit, updated the diary each day and gathered documents, returning for the final appointment to complete the form with the lead researcher (undertaken as an advisor). After completion of the form, each trial ended with an audiorecorded semi-structured interview, where the claimant was asked about their experiences of using PIP Kit. The lead researcher also made a note of his own reflections immediately afterwards. Research data comprising the small number of claimant diaries and full interview transcripts were subject to inductive thematic analysis [45]. The researcher's field notes were only used to verify factual information, and were not used in analysis to avoid bias.

\section{FINDINGS: PROTOTYPE DEPLOYMENT STUDY}

\section{Empowerment (of claimants)}

Selection of Diary Modules: Claimants have few choices in the standard PIP claim process. PIP Kit gave participants a choice of content modules, technology components and (if desired) task prompts or appointment reminders. On the modules selected, $\mathrm{C} 2$ noted "your little cards pretty much hit every spot" and "I think every title fitted my needs". PIP Kit gave a degree of control over diary use.

Technology Choices: Participants seemed most confident with digital devices like phones and cameras, rather than other forms of computers, consistent with what advisors had said in Workshop 2 of Study 1. No-one chose the fully online diary option. C1 said they no longer use the internet as "I don't have a phone" having sold it to raise money. As a competent technology user $\mathrm{C} 2$ has access to computers at friends and public libraries, and has a smartphone with a generous data plan, but finds the screen size limiting and only uses the internet "when I need it". They chose not to use the online diary option because the physical paper cards could be laid out, sorted and arranged, and there was no fear of losing information. Having used it $\mathrm{C} 2$ would still prefer the 
paper cards "because it's a hands-on thing... I felt more comfortable being able to use both hands [unlike a mouse]" and "it is easy to see it out laid... in front of me". C3 preferred "to do things hands on rather than computers" due to a health-condition causing problems with dexterity.

Prompts and Reminders: Participants did not want PIP Kit's optional scheduled reminders to complete the diary, but two did ask for reminders for the subsequent final formfilling appointment (one by an automated SMS and one by a manually initiated telephone call). During the interview, C2 said they found "remembering to use [PIP Kit] difficult and forgot on some days, suggesting the cards should have " $a$ box maybe" for each day because "you know... the day you started... so I would have a starting point... and could look back and say where's Thursday and Friday". C3 emphasised that adding 'day structure' would help to make sure they completed it each day and also suggested using colour as a way to indicate 'yes/no' choices.

Reduction in Complexity: Use of PIP Kit reduced feelings of complexity. C2 said PIP Kit "individualised... overwhelming things like... um, sort of, put them into little [compartments] ...yes" so that "rather address the whole situation, I was able to... stop deal with that one, ... stop deal with that one, so it caused less stress". C2 added that breaking the problem down "helped mentally" in dealing with the PIP claim process.

Photographic Records: The camera was popular, wellutilised and used in preference to their own smartphone for capturing images. All participants chose to take the digital camera, taking multiple pictures of rooms and aids at home. $\mathrm{C} 2$ noted it would have caused " $a$ bit more anxiety for me without the pictures" and "found the pictures a better aid than verbal". When asked if PIP Kit was easy to use, C2 said "personally yes, it was fine" and C3 supported this opinion. All participants shared and discussed every photo.

\section{Revelation (of supporting information)}

Preparation for Form-Filling Appointment: PIP Kit helped preparations for the assisted final form-filling appointment and discussions to make their case for an award. C1 said it was a "help" and was "very good" and C2 described how it assisted gathering information into one place "it made sure that I was organised, had the right form" and C3 said PIP Kit helped them know what they were doing and how to explain and express "what I'm feeling.... so that was preparing me for [the appointment]".

Supporting the Claimant's Case for an Award: The PIP Kit materials brought by the claimants produced content which supported the claimants' cases and were therefore copied for inclusion in their submissions as supporting evidence. Indeed, the PIP Kit diary entries and photos were noted to be of assistance for discussing and writing up multiple activities, as indicated in Table 1. In the event, $\mathrm{C} 1$ used two diary modules for 3 weeks and also took 5 photographs. C2 used four diary modules for 1 week and took 13 photographs. C3 used three diary modules for one week and took 6 photographs.

\begin{tabular}{|l|c|c|c|}
\hline PIP Assessed Activity & C1 & C2 & C3 \\
\hline Preparing food & & & \\
\hline Eating and drinking & & & NA \\
\hline Managing treatments & & & \\
\hline Washing and bathing & & & \\
\hline Managing toilet needs & & NA & \\
\hline Dressing and undressing & NA & NA & NA \\
\hline Communicating & NA & NA & NA \\
\hline Reading & & & \\
\hline Mixing with other people & NA & NA & NA \\
\hline Money decisions & & & \\
\hline Going out & & & \\
\hline Moving around &
\end{tabular}

Table 1. PIP activity versus PIP Kit data utilisation for each claimant (C1-C3) indicating format as paper and online daily record or digital photograph. Activities not affecting an individual participant are indicated NA. Blank indicates a relevant issue but PIP Kit data was not utilised.

PIP Kit's outputs provided a visual quick reference while discussing the assessed activities. The visual nature of the paper cards helped claimants voice their personal difficulties with C3 noting "if I found it hard to explain, at least it was there, the dots were there to show that how I felt" providing quantification at a glance "you know that how many dots you've put, so you know which days".

Improved Focus: PIP Kit helped participants concentrate on the most important matters to justify their claim In comparison to direct verbal-only conversation during both the initial and final appointments, claimant C2 said they stayed "a bit focused" and were less prone to "stray off" onto other matters while referring to the diary entries and photos. C2 themselves said they found the diary "helped immensely" because of "struggling with memories". This streamlines discussions with the form-filling advisor.

Photo-Elicitation: Photographs supported discussions and provided evidence for submission with the claim form. C2 commented on how the digital camera photos are "very strong" and added much to the discussion during the formfilling appointment "the pictures say a lot, don't they?" adding they were an "advocate". Claimant C2, who had made previous PIP claims, said they would "never of thought of further evidence as pictures". The researchers noted the digital photos "revealed aids which might not have been discussed otherwise". C1's photos of the step at their home's front door and stairs (Figure 3) inside did not directly relate to an assessed PIP activity, but the researcher recorded in field notes that these "led to a discussion about problems going to the kitchen since this is on a different level to the bathroom", thus providing points to expand upon through discussion. 


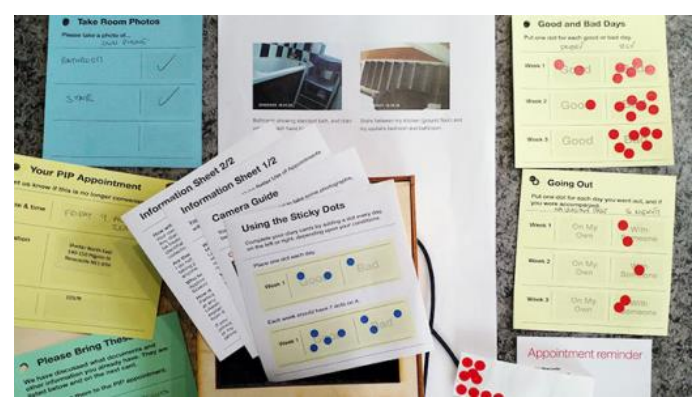

Figure 3: Claimant C1's PIP Kit returned records and photos.

Hope (for the assessment process)

Increased Understanding and Confidence: During the trials, claimants seemed more engaged with the PIP process and expressed how the components help them to break down the larger problem into more understandable parts. $\mathrm{C} 2$ noted "I feel that we've given more information than the last time I filled the form in". $\mathrm{C} 2$ was very familiar with the PIP claim process having made two previous unsuccessful claims, permitting some comparison with using PIP Kit this time "because everything was compartmentalised... I didn't feel so overwhelmed... I had a better understanding of what we were answering and what's needed". The researchers noted that $\mathrm{C} 1$ had been "less able to differentiate the benefits of using a diary" but $\mathrm{C} 3$ was also a first time claimant and said PIP Kit "helped me towards the assessment as well". C2 and C3 said the diary would be useful to others "especially those who have lesser understanding [of PIP] " and would want to use it again themselves for any future reassessments.

Quality Matters: Participants valued the effort taken to listen to and understand them, and to give them time enabling them to make choices and contributions, without just feeling part of a process they have no control over. At the end of the interview C2 noted "obviously the little kit itself is quite well presented" and "everything else was spot on", going on to say using PIP Kit was "definitely a benefit. I enjoyed it". Claimants liked the physicality of PIP Kit, especially its handmade craftwork nature, even when a completely digital choice was available. C3 added "I was fascinated" saying "it looks nice... amazing... compact" and is "professional".

\section{DISCUSSION}

\section{Digital Services for Disability Benefits Claimants}

Our findings from both groups of participants show that claimants are overwhelmed by claims and assessments. We found that the approach offered by PIP Kit helped ameliorate this, with claimants feeling better able to grasp the purpose of the assessment questions and focused more upon the effects of their conditions rather than the conditions themselves. PIP Kit's granularity also generated memory cues as conversation starters leading to further supporting evidence. There is a notable contrast between the approach afforded by PIP Kit and the rigid, legalistic and processcentric public services offered by states (e.g. as with PIP). This concern is particularly important in the move to digital services, as retaining a process-centric approach will introduce additional barriers, even when people have access to suitable technology and internet access. Our findings suggest that small interventions, such as PIP Kit, can produce increased engagement with processes that would be otherwise inaccessible, thus evidencing a clear route towards making reasonable accommodations for claimants by the state.

We found a reluctance to use existing digital technologies, with these being seen as awkward and complex. Advisors highlighted that email and websites were particularly disliked by claimants, but they had a much greater affinity for using smartphones. All claimants chose the paper diary (and gave compelling reasons as to their preference for avoiding more technology orientated approaches), but an acceptance of using a camera to take photographs. To increase uptake of digital options, these should be lightweight and easy to use by all types of people requiring as little experience, skills and knowledge as possible. Future designs should focus on development of simple but separate artifacts that provide assistance with the task at hand.

\section{Lifelogging Experiences of Disability}

Making a disability benefits claim can be conceptualised as a novel form of lifelogging task, namely that of documenting the effects of someone's disability to align with the rigid criteria expected by the state. This population is vulnerable due to their long-term health conditions and disabilities, and in many cases have barriers in expressing themselves. The need to have ownership of the process, respect of privacy and to ensure claimant engagement, necessitated a lifelogging approach with different qualities to the traditional approach that captures a large volume of data [34]. The main distinction is the provision of a minimalist, self-directed approach, where information capture is entirely at the subjects' discretion and under their own control (which also has the advantage of being more privacy sensitive).

The reason we are able to adopt such an approach lies with the role of the benefits advisor, who is able to take the claimant through the photographs with the broad-brush selfcurated sample of a subset of daily living using the day reconstruction diary provided being simply the starting point for a discussion. In effect, the raw data acted as a seed upon which to expand and reveal additional unstructured data from conversation between the claimant and advisor. The 'retrieval' step was the benefit claimant themselves showing and discussing what they collected with an advisor, illustrating the advantages of having human support in such a process and the opportunity this affords for innovative approaches to lifelogging.

Design Considerations for Disability Benefits Claimants In addition to the translation of the process into a lifelogging task, we have identified four further considerations for supporting disability benefit claimants with their claim:

A. Process Simplification: We found that the scale of interaction required from a claimant should be predicated on 
reducing the complexity of the task at hand (including how this is perceived by the claimant), thereby ensuring that the system meets each individuals' threshold for coping and comprehension, so they retain some degree of control. The reports of our participants emphasised that claimants have wide-ranging conditions and impairments, and systems should encompass a broad set of features to cater for these. As such, the process should be simplified by not presenting everything at once in the initial meeting, personalisation (only including what is most relevant to each claimant and not aiming to "design for all" [51]), and acknowledging that lifelogging need not capture all required data but can be successfully used as part of a larger exercise. For the latter, the materials for the diary were collected for a subsequent discussion between claimant and advisor. They acted like story completion stubs [15], which could be referred to and expanded upon. This is different to many active lifelogging systems where data extraction and analysis becomes a significant task. It suggests that in the context of information gathering with this group of people, less data capture during lifelogging may lead to more insight, provided it can be combined with a discussion reflecting on those records.

B. Visual Cues and Photography: We found photography was a vital part of supporting the claim process. The claimants easily adopted the invitation to selectively capture and retain photographs (in line with [16]). These included images of areas of their homes where they experienced particular difficulties and aids that helped them cope affording an independent insight to claimants' daily lives. Automated time stamping provided a form of organisation, helping them recollect and express their at-home situations. The images sometimes revealed more than realised, reflecting how people normalise their own situations and find it difficult to identify what they are doing that is different. The physical paper cards with stickers likewise afforded being used as visual cues. Such visual representations helped in simplifying the process (per Point A above), and in acting as 'boundary objects' [1] facilitating communication.

C. Offer Flexibility and Control: We identified that people with long-term health conditions and disabilities feel they have little control over the outcomes of interactions with government systems, such as for benefit claims, and become depressed and demoralised by the process. Choices are known to stimulate engagement and the provision of options helps address the diverse needs [61] relating to different types of conditions/effects [51]. We first gave the claimants the feeling of being in control by choosing the nature of interactions with the toolkit (e.g. digital or selecting from two physical paper card options). Secondly, more flexibility and control is offered by the fact that our approach allowed the claimants to prepare at home (using the diary within the context of their normal routines), rather than having to 'recollect' at the office helping address the known issue that claimants often find it difficult to remember [43] or selfassess [44,59] their own situations. More generally, our findings support the need to offer flexibility and control when designing for claimants, noting it offered increased engagement, and can improve claimant's self-confidence.

D. Personal Aesthetics: We found that an aesthetically pleasing approach helped claimants deal with what is otherwise a distressing activity. In practice, the laser-cut box created for the initial probe was a popular discussion point with advisors which steered the enclosure design for the PIP Kit prototype's physical components. All of the claimants expressed their appreciation of the craft-like nature, far removed from the design of many clinical products, with two claimants reluctant to return the box.

\section{Wider Implications, Limitations and Future Work}

We have contributed to an ethically-informed approach to investigating innovations in the disability claims process. The prototype trials were promising, demonstrating how lifelogging can adapt the government process as well as making the process more humane from claimants' points of view. This work offers particular design considerations for developing assistive technology (AT) for disability benefits claimants, who are an important population to be considered specifically going forwards when designing AT more generally. Notably, our study concerned only one benefits payment in the UK at first stage of the process, with a small number of claimants, and using a dual role researcheradvisor, limiting the generalisability of findings. Future work could trial our approach in different benefits systems, or addresses a different stage of the application process (e.g. the health assessment). Another limitation is that our participant pool was constrained to those with full mental capacity: future work could explore (ethically) supporting those with impairments that particularly limit their ability to articulate their experiences. Going forwards, there is also an important cautionary point to consider: a more advanced lifelogging system imposed on claimants by government departments could undermine a disability benefit claim as well as support it. Whilst this avenue of work holds much promise when designed to support claimants, it is important to be alive to the wider human rights issues and risks if such a system were to be inappropriately adapted.

\section{CONCLUSION}

This paper investigated the use of daily elicitation diaries to capture the day-to-day variations in the effects of people's health conditions and disabilities on their lives. The research findings provide an insight into the problems people have dealing with inflexible complex transactional government services, highlight the importance of familiarity for technology interventions, and demonstrate the need for increased customisability and ways to gather assessment information using a daily diary method that is tailored to their conditions, their abilities and other events in their lives.

\section{ACKNOWLEDGEMENTS}

We are very grateful to Shelter for facilitating this research. This work was funded through the EPSRC Centre for Doctoral Training in Digital Civics at Newcastle University (EP/L016176/1). Data is not available due to confidentiality. 


\section{REFERENCES}

[1] Sanne F Akkerman and Arthur Bakker. 2011. Boundary crossing and boundary objects. Review of educational research 81, 2: 132-169.

[2] Katrina Allen, Catherine Hale, Katharine Seton, and Julia Newton. 2016. A deeply dehumanising experience - M.E./CFS journeys through the PIP claim process in Scotland. Action for ME. Retrieved September 8, 2019 from https://www.actionforme.org.uk/uploads/pip-reportscotland.pdf

[3] Meghan Allen, Joanna McGrenere, and Barbara Purves. 2008. The Field Evaluation of a Mobile Digital Image Communication Application Designed for People with Aphasia. ACM Trans. Access. Comput. 1, 1: 5:1-5:26. https://doi.org/10.1145/1361203.1361208

[4] Alston, Philip. 2018. Statement on Visit to the United Kingdom, by Professor Philip Alston, United Nations Special Rapporteur on extreme poverty and human rights. Office of the High Commissioner for Human Rights, United Nations. Retrieved September 4, 2019 from https://www.ohchr.org/EN/NewsEvents/Pages/Display News.aspx?NewsID $=23881 \&$ LangID $=E$

[5] Michael Asimow. 2015. Five models of administrative adjudication. The American Journal of Comparative Law 63, 1: 3-32.

[6] Amid Ayobi, Tobias Sonne, Paul Marshall, and Anna Cox. 2018. Flexible and Mindful Self-Tracking: Design Implications from Paper Bullet Journals. 1-14. https://doi.org/10.1145/3173574.3173602

[7] Carla Ayrton, Karen Barker, Adam Tinson, Theo Barry Born, Hannah Aldridge, Peter Kenway, Joseph Rowntree Foundation, and New Policy Institute. 2016. Monitoring poverty and social exclusion 2016. Joseph Rowntree Foundation. Retrieved from https://asauk.org.uk/wpcontent/uploads/2018/02/2016_mpse_uk_2016_final_r eport.pdf

[8] Daniela Q.C.M. Barge-Schaapveld, Nancy A. Nicolson, Philippe A.E.G. Delespaul, and Marten W. deVries. 2006. Assessing Daily Quality of Life with the Experience Sampling Method. In Quality of Life in Mental Disorders (Second Edi), Heinz Katschnig, Hugh Freeman and Norman Sartorius (eds.). John Wiley \& Sons.

[9] Ben Baumberg. 2016. The stigma of claiming benefits: a quantitative study. Journal of Social Policy 45, 2: 181-199. https://doi.org/10.1017/S0047279415000525

[10] Jerome Bickenbach, Aleksandra Posarac, Alarcos Cieza, and Nenad Kostanjsek. 2015. Assessing Disability in Working Age Population A Paradigm Shift: from Impairment and Functional Limitation to the Disability Approach.

[11] Marc Bolaños, Mariella Dimiccoli, and Petia Radeva. 2017. Towards Storytelling from Visual Lifelogging: An Overview. IEEE Transactions on Human-Machine
Systems: $1-14$.

https://doi.org/10.1109/THMS.2016.2616296

[12] Niall Bolger, Angelina Davis, and Eshkol Rafaeli. 2003. Diary Methods: Capturing Life as it is Lived. Annual Review of Psychology 54, 1: 579-616. https://doi.org/10.1146/annurev.psych.54.101601.1450 30

[13] LouAnne E. Boyd, Kyle Rector, Halley Profita, Abigale J. Stangl, Annuska Zolyomi, Shaun K. Kane, and Gillian R. Hayes. 2017. Understanding the Role Fluidity of Stakeholders During Assistive Technology Research "In the Wild." In Proceedings of the 2017 CHI Conference on Human Factors in Computing Systems (CHI '17), 6147-6158. https://doi.org/10.1145/3025453.3025493

[14] Dawn O. Braithwaite, Teresa L. Thompson, and Teresa L. Thompson. 1999. Handbook of Communication and People With Disabilities : Research and Application. Routledge. https://doi.org/10.4324/9781410603647

[15] Virginia Braun, Victoria Clarke, Nikki Hayfield, Hannah Frith, Helen Malson, Naomi Moller, and Iduna Shah-Beckley. 2019. Qualitative story completion: Possibilities and potential pitfalls. Qualitative Research in Psychology 16, 1: 136-155.

[16] Scott Carter and Jennifer Mankoff. 2005. When participants do the capturing. In Proceedings of the SIGCHI conference on Human factors in computing systems - CHI '05, 899. https://doi.org/10.1145/1054972.1055098

[17] Raymond Chan, Glenn Gardner, Joan Webster, and Alanna Geary. 2010. Building research capacity in the nursing workforce: The design and evaluation of the nurse researcher role. Australian Journal of Advanced Nursing 27.

[18] Stevie Chancellor, Nazanin Andalibi, Lindsay Blackwell, David Nemer, and Wendy Moncur. 2019. Sensitive Research, Practice and Design in HCI. In Extended Abstracts of the 2019 CHI Conference on Human Factors in Computing Systems (CHI EA '19), W33:1-W33:8. https://doi.org/10.1145/3290607.3299003

[19] Citizens Advice. Help filling in your PIP claim form Citizens Advice. Retrieved July 2, 2019 from https:/www.citizensadvice.org.uk/benefits/sick-ordisabled-people-and-carers/pip/help-with-yourclaim/fill-in-form/

[20] Citizens' Advice. 2015. Keep a record of how your condition affects you. citizensadvice.org.uk. Retrieved July 28, 2019 from https://www.citizensadvice.org.uk/Documents/Advice (public)/pip-diary.pdf

[21] Tamlin Conner Christensen, Lisa Feldman Barrett, Eliza Bliss-Moreau, Kirsten Lebo, and Cynthia Kaschub. 2003. A Practical Guide to ExperienceSampling Procedures.

[22] Department for Work and Pensions. Personal Independence Payment (PIP) assessment guide for 
assessment providers - GOV.UK. 2013-2019.

Retrieved July 2, 2019 from

https://www.gov.uk/government/publications/personalindependence-payment-assessment-guide-forassessment-providers

[23] Department for Work and Pensions. 2015. Personal Independence Payment - How your disability affects you - information booklet (specimen PIP2 information booklet). gov.uk. Retrieved July 28, 2019 from https://assets.publishing.service.gov.uk/government/up loads/system/uploads/attachment_data/file/584201/pip 2-information-booklet.pdf

[24] Department for Work and Pensions. 2018. Personal Independence Payment - How your disability affects you (specimen PIP2 form). gov.uk. Retrieved July 28, 2019 from

https://assets.publishing.service.gov.uk/government/up loads/system/uploads/attachment_data/file/713118/pip 2-how-your-disability-affects-you-form.pdf

[25] Department for Work and Pensions. 2018. Personal Independence Payment (PIP) handbook. Department for Work and Pensions. Retrieved from https://assets.publishing.service.gov.uk/government/up loads/system/uploads/attachment_data/file/757816/PIP -handbook.pdf

[26] Disability Benefits Consortium. 2019. Has Welfare Become Unfair - The impact of welfare changes on disabled people. Disability Benefits Consortium. Retrieved September 8, 2019 from https://www.rethink.org/media/2494/has-welfarebecome-unfair-full-report.pdf

[27] DWP. 2019. Personal Independence Payment: Official Statistics Quarterly - Data to January 2019. Retrieved July 31, 2019 from

https://assets.publishing.service.gov.uk/government/up loads/system/uploads/attachment_data/file/786587/pipstatistics-to-january-2019.pdf

[28] Ingrid V Eagly. 2014. Remote adjudication in immigration. Nw. UL Rev. 109: 933.

[29] Extra Costs Commission. 2016. Driving down the extra costs disabled people face - Final report. Extra Costs Commission. Retrieved September 8, 2019 from https://www.barrowcadbury.org.uk/wpcontent/uploads/2015/06/Extra-Costs-CommissionFinal-Report.pdf

[30] Heather A. Faucett, Kate E. Ringland, Amanda L. L. Cullen, and Gillian R. Hayes. 2017. (In)Visibility in Disability and Assistive Technology. ACM Trans. Access. Comput. 10, 4: 14:1-14:17. https://doi.org/10.1145/3132040

[31] Maria Angela Ferrario, Will Simm, Peter Newman, Stephen Forshaw, and Jon Whittle. 2014. Software engineering for "social good": integrating action research, participatory design, and agile development. https://doi.org/10.1145/2591062.2591121

[32] Rachel Gibson, Marta Cantijoch, and Silvia Galandini. 2014. The Third Sector and Online Citizen
Empowerment: the Case of mySociety. University of Manchester. Retrieved September 2, 2019 from https://www.research.manchester.ac.uk/portal/files/325 51263/FULL_TEXT.PDF

[33] Steven Graby. 2015. Access to work or liberation from work? Disabled people, autonomy, and post-work politics. Canadian Journal of Disability Studies 4, 2: 132-161. https://doi.org/10.15353/cjds.v4i2.212

[34] Cathal Gurrin, Alan F. Smeaton, and Aiden R. Doherty. 2014. LifeLogging: Personal Big Data. Found. Trends Inf. Retr. 8, 1: 1-125. https://doi.org/10.1561/1500000033

[35] Jennifer Harris. 2019. The digitization of advice and welfare benefits services: re-imagining the homeless user. Housing Studies: 1-20. https://doi.org/10.1080/02673037.2019.1594709

[36] M. Harvey, M. Langheinrich, and G. Ward. 2016. Remembering through lifelogging: A survey of human memory augmentation. Pervasive and Mobile Computing 27: 14-26.

[37] E. Jean C. Hay-Smith, Melanie Brown, Lynley Anderson, and Gareth J. Treharne. 2016. Once a clinician, always a clinician: a systematic review to develop a typology of clinician-researcher dual-role experiences in health research with patientparticipants. BMC Medical Research Methodology 16, 1: 95. https://doi.org/10.1186/s12874-016-0203-6

[38] Turid Heiberg, Tore K. Kvien, Øystein Dale, Petter Mowinckel, Gerd J. Aanerud, Ann B. Songe-Møller, Till Uhlig, and Kåre B. Hagen. 2007. Daily health status registration (patient diary) in patients with rheumatoid arthritis: A comparison between personal digital assistant and paper-pencil format. Arthritis \& Rheumatism 57, 3: 454-460. https://doi.org/10.1002/art.22613

[39] Steve Hodges, Lyndsay Williams, Emma Berry, Shahram Izadi, James Srinivasan, Alex Butler, Gavin Smyth, Narinder Kapur, and Ken Wood. 2006. SenseCam: A Retrospective Memory Aid. In UbiComp 2006: Ubiquitous Computing (Lecture Notes in Computer Science), 177-193.

[40] Karen Holtzblatt and Hugh Beyer. 1998. The Affinity Diagram. In Contextual Design. Morgan Kauffman Publishers, 154-163. https://doi.org/10.1016/b978-012-800894-2.00006-5

[41] Lauri L. Hyers. 2017. Diary Methods: Understanding Qualitative Research. Oxford University Press.

[42] Tanya M. Judkins-Cohn, Kiersten KielwasserWithrow, Melissa Owen, and Jessica Ward. 2014. Ethical principles of informed consent: exploring nurses' dual role of care provider and researcher. Journal of Continuing Education in Nursing 45, 1: 3542. https://doi.org/10.3928/00220124-20131223-03

[43] Daniel Kahneman and Jason Riis. 2012. Living, and thinking about it: Two perspectives on life. In The Science of Well-Being. 
https://doi.org/10.1093/acprof:oso/9780198567523.003 .0011

[44] Aaron Lazare. 1987. Shame and Humiliation in the Medical Encounter. Archives of Internal Medicine 147. https://doi.org/10.1001/archinte.1987.00370090129021

[45] Susan Luckman. 2016. Virginia Braun and Victoria Clarke, Successful qualitative research: A practical guide for beginners . Feminism \& Psychology. https://doi.org/10.1177/0959353515614115

[46] Juan Maestre, Elizabeth Eikey, Mark Warner, Svetlana Yarosh, Jessica Pater, Maia Jacobs, Gabriela Marcu, and Patrick Shih. 2018. Conducting Research with Stigmatized Populations: Practices, Challenges, and Lessons Learned. 385-392. https://doi.org/10.1145/3272973.3273003

[47] Christine Milligan and Ruth Bartlett. 2019. Solicited Diary Methods. In Handbook of Research Methods in Health Social Sciences. Springer Singapore, Singapore, 1447-1464. https://doi.org/10.1007/978981-10-5251-4_15

[48] MS Society. PIP - diary template (PDF). mssociety.org.uk. Retrieved July 28, 2019 from https://www.mssociety.org.uk/care-andsupport/resources-and-publications/publicationssearch/pip---diary-template-pdf

[49] MS Society. 2016. Claiming PIP. Retrieved from https://mss-cdn.azureedge.net//media/bd27020bc21c4c15aeb98b81d43a7384.pdf?sc revision $=2892 \mathrm{e} 01 \mathrm{ce} 0784 \mathrm{e} 0 \mathrm{cae} 7 \mathrm{bc} 7 \mathrm{f5b} 496 \mathrm{~b} 2 \mathrm{aa}$

[50] A. F. Newell, P. Gregor, M. Morgan, G. Pullin, and C. Macaulay. 2011. User-Sensitive Inclusive Design. Universal Access in the Information Society 10, 3: 235-243. https://doi.org/10.1007/s10209-010-0203-y

[51] Alan F. Newell and Peter Gregor. 2000. User Sensitive Inclusive Design - in Search of a New Paradigm. In Proceedings on the 2000 Conference on Universal Usability (CUU '00), 39-44. https://doi.org/10.1145/355460.355470

[52] OECD Directorate for Employment, Labour and Social Affairs. 2009. Sickness, Disability and Work - Keeping on Track in the Economic Downturn. OECD. Retrieved from http://www.oecd.org/employment/emp/42699911.pdf

[53] Stephen James Pacey. 2015. Judging the judge: boundaries, barriers and benefits. Middlesex University.

[54] Burak Pak, Alvin Chua, and Andrew Vande Moere. 2017. FixMyStreet Brussels: Socio-Demographic Inequality in Crowdsourced Civic Participation. Journal of Urban Technology 24, 2: 65-87. https://doi.org/10.1080/10630732.2016.1270047

[55] Harry T Reis and S. L. (2000). Gable. 2000. Eventsampling and other methods for studying everyday experience. In. In Handbook of research methods in social and personality psychology (pp. https://doi.org/10.1016/j.jssc.2010.05.013
[56] Rozenberg, Joshua. 2019. The Online Court: will IT work? Legal Education Foundation.

[57] Jessica Saffer. 2017. Responses of People With Physical Health Conditions to Changes in Disability Benefits: A Grounded Theory Study. University of Hertfordshire. Retrieved September 8, 2019 from http://uhra.herts.ac.uk/handle/2299/19513

[58] Shannon Salter and Darin Thompson. 2017. PublicCentred Civil Justice Redesign: A Case Study of the British Columbia Civil Resolution Tribunal. McGill Journal of Dispute Resolution 3: 2016-2017.

[59] Gabi Schaffzin. 2018. Reclaiming the Margins in the Face of the Quantified Self. Review of Disability Studies: An International Journal 14, 2. Retrieved September 8, 2019 from https://rdsjournal.org/index.php/journal/article/view/81 3

[60] Scottish Government. 2016. International Comparison of Disability Benefits.

[61] Kristen Shinohara, Cynthia L. Bennett, Wanda Pratt, and Jacob O. Wobbrock. 2018. Tenets for Social Accessibility: Towards Humanizing Disabled People in Design. ACM Trans. Access. Comput. 11, 1: 6:16:31. https://doi.org/10.1145/3178855

[62] Anna Ståhl, Kristina Höök, Martin Svensson, Alex S. Taylor, and Marco Combetto. 2009. Experiencing the affective diary. Personal and Ubiquitous Computing. https://doi.org/10.1007/s00779-008-0202-7

[63] Robert Thomas. 2016. From “Adversarial V Inquisitorial" to "Active, Enabling, and Investigative": Developments in UK Administrative Tribunals. In The Nature of Inquisitorial Processes in Administrative Regimes. Routledge, 65-84.

[64] Dane Thorley and Joshua Mitts. 2019. Trial by Skype: A Causality-Oriented Replication Exploring the Use of Remote Video Adjudication in Immigration Removal Proceedings. International Review of Law and Economics.

[65] UK Government. 2005. Mental Capacity Act 2005. Retrieved January 6, 2020 from http://www.legislation.gov.uk/ukpga/2005/9/contents

[66] UK Government. 2013. The Social Security (Personal Independence Payment) Regulations 2013. Retrieved January 6, 2020 from http:/www.legislation.gov.uk/uksi/2013/377/made

[67] UK Government. 2013. The Social Security (Personal Independence Payment) (Amendment) Regulations 2013. Retrieved January 6, 2020 from http://www.legislation.gov.uk/uksi/2013/455/contents/ made

[68] UN Committee on the Rights of Persons with Disabilities. 2017. Concluding observations on the initial report of the United Kingdom of Great Britain and Northern Ireland. United Nations. Retrieved December 5, 2019 from http://docstore.ohchr.org/SelfServices/FilesHandler.ash $\mathrm{x}$ ?enc $=6 \mathrm{QkG} 1 \mathrm{~d} \% 2 \mathrm{fPPRiCAqhKb} 7 \mathrm{yhspCUnZhK1jU6}$ 
6fLQJyHIkqMIT3RDaLiqzhH8tVNxhro6S657eVNwu qlzu0xvsQUehREyYEQD\%2bldQaLP31QDpRcmG35 KYFtgGyAN\%2baB7cyky7

[69] Brunel University. 2002. Definitions of Disability in Europe: A Comparative Study.

[70] Beth Watts, Glen Bramley, Janice Blenkinsopp, and Jill Mcintyre. 2019. Homelessness prevention in Newcastle: Examining the role of the "local state" in the context of austerity and welfare reforms.
[71] Stephen Weatherhead. 2014. The media-based stigmatisation of people who access benefits. No 257: 8-10.

[72] Jacob O. Wobbrock, Krzysztof Z. Gajos, Shaun K. Kane, and Gregg C. Vanderheiden. 2018. Abilitybased Design. Commun. ACM 61, 6: 62-71. https://doi.org/10.1145/3148051

[73] Patricia de Wolfe. 2012. Reaping the benefits of sickness? Long-term illness and the experience of welfare claims. Disability \& Society 27, 5: 617-630. https://doi.org/10.1080/09687599.2012.669107 